\title{
METÁFORAS MULTIMODAIS: A PERCEPÇÃO DA PANDEMIA DE COVID- 19 ATRAVÉS DE CHARGES
}

\author{
MULTIMODAL METAPHORS: \\ THE PERCEPTION OF COVID'S \\ PANDEMIC THROUGH CHARGES
}

\author{
Ricardo Yamashita Santos' \\ Universidade Potiguar
}

Resumo: Este artigo analisa de forma qualitativa o modo como a pandemia da COVID-19 é descrita em três charges selecionadas através de pesquisa no buscador Google. Utilizando o cabedal teórico oriundo da Linguística Cognitiva, pretendemos compreender como o discurso a respeito da pandemia tem sido construído, enfatizando o olhar sobre algumas estruturas cognitivas, como a metáfora e o frame que alicerçam a organização conceitual das charges selecionadas. Desse modo, o frame que é enquadrado na charge é subsidiado por uma metáfora multimodal que constrói determinado efeito discursivo, como ironia, humor etc. Esse efeito de sentido permite analisarmos alguns dos aspectos que têm construído os modelos culturais, com vistas a reflexão sobre este cenário em que nos encontramos. Entender COVID-19 como uma doença viral nos permite dimensionar o processo discursivo pelo qual a pandemia tem sido compreendida.

Palavras-Chave: Charges; Covid-19; Metáfora multimodal; Modelos Culturais.

1 Endereço eletrônico: ricardo.yama@yahoo.com.br 
Abstract: This article qualitatively analyzes how the COVID-19 pandemic is described in three cartoons selected through a search on Google. Using the theoretical background from Cognitive Linguistics, we intend to understand how the discourse about the pandemic has been constructed, emphasizing the look at some cognitive structures, such as the metaphor and the frame that underlie the conceptual organization of the selected cartoons. In this way, the frame that is included in the cartoon is subsidized by a mutimodal metaphor that builds a certain discursive effect, such as irony, humor, etc. This effect of meaning allows us to analyze some of the aspects that have built cultural models, with a view to reflecting on this scenario in which we find ourselves. Understanding COVID-19 as a viral disease allows us to measure the discursive process by which the pandemic has been understood.

Keywords: Charges; Covid-19; Multimodal metaphor; Cultural Models.

\section{INTRODUÇÃO}

As discussões que têm norteado a Linguística Cognitiva (LC) contemporânea refinam cada vez mais determinadas categorias analíticas, como as metáforas conceptuais, inauguradas por Lakoff e Johnson (1980), e os frames, propostos, inicialmente, por Minsky $(1985)^{2}$ e Fillmore (1976). Essas categorias de análise, atualmente, não podem mais ser entendidas de forma estanque, uma vez que os avanços nas neurociências comprovam que os acionamentos conceituais em nossos cérebros são simultâneos, ocorrendo ao mesmo tempo e em fração de milissegundos.

Essas categorias de análise, bem como o escopo teórico que delineia a proposta, fazem parte de um arcabouço que vai além da própria delimitação da LC. Diversas abordagens estão sendo formuladas para a observação da LC de segunda geração, pós mente modular. Porém, duas delas se tornaram nosso foco maior de observação: os Modelos Culturais e frames culturais. Feltes (2018) utiliza o conceito de Modelos Culturais através da interface linguagem, cultura e cognição. Esse conceito, nas últimas quatro décadas, se estrutura a partir de diferentes modelos teóricos, em campos de investigação diversos (por exemplo, Antropologia, Ciências Cognitivas, Inteligência Artificial). Nosso cabedal teórico

\footnotetext{
${ }^{2}$ Sobre Inteligência Artificial.
} 
dialoga também com Duque $(2015,2017)$ que insere a discussão a partir da concepção de frames culturais.

Os Modelos Culturais abrangem diversas áreas e campos de atuação, tendo como principal escopo a linguagem associada aos processos cognitivos inseridos nas culturas. Nos tópicos seguintes iremos contextualizar melhor a proposta de Modelos Culturais para em seguida propormos uma análise de charges que contemplem a COVID-19. Essa análise foi realizada em charges retiradas da internet e são referentes ao contexto do Brasil em meados do primeiro semestre do ano de 2020.

Na sequência, iremos apresentar os aspectos teóricos da LC que nos interessa, passando para a descrição da metodologia e posterior análise das charges. Ao término, faremos um tópico de conclusão para discutir os resultados e apontar possíveis desdobramentos.

\section{LINGUÍSTICA COGNITIVA E MODELOS CULTURAIS}

Bennardo e Munck (2014), cuja obra é uma espécie de manual sobre fundamentos, teorias, métodos e aplicações relativos a modelos culturais, entendem, de modo geral, que modelos culturais são representações ou configurações mentais de conteúdo cultural minimamente saliente, compartilhadas por membros de uma cultura, as quais funcionam na perspectiva de dar sentido e interpretar inputs sensoriais, assim como produzir e dar forma a comportamentos intencionais e comunicativos. Não se tratam de operações cognitivas, mas de estocagem da experiência na mente por meio de inputs culturais.

Como nos lembra Feltes (2018), tecendo comentários a respeito da proposta de Bennardo e Munck, os Modelos Culturais são tipicamente flexíveis e fluidos. Isso se justifica pelo fato de que as pessoas podem não estar conscientes deles ou porque eles estão além da capacidade de elas os articularem. Esses 
modelos, como consequência, são usados em uma ampla variedade de situações por pessoas com diferentes perspectivas ou características psicológicas (por exemplo, história de vida, idade, status social).

De um modo geral, podemos dizer que os Modelos Culturais nos auxiliam a:

- Organizar formas de agir e o que esperar de reação social (KRONENFELD, 2008) e

- $\quad$ Organizar estruturas molares de conhecimento, ou organizações molares, cuja estrutura interna é composta de um núcleo (core) e nós "periféricos" que são preenchidos por valores padrão (default);

D'Andrade (1992) define modelo cultural (ou modelo folk) como "um esquema cognitivo que é intersubjetivamente compartilhado por um grupo social". Para o autor, o modelo cultural é um padrão genérico que auxilia na catalogação de atividades, eventos ou objetos específicos a partir de um dado contexto em que ele necessariamente está inserido.

Quinn (1997), com outras palavras, mas com propósitos semelhantes, afirma que Modelos Culturais são esquemas culturais complexos que organizam todos os tipos de domínios de experiências, sejam eles de natureza perceptual, conceitual, relativos a objetos ou eventos, com o propósito de elaborar sistemas de conhecimento.

Strauss (2014), na mesma linha de pensamento, trata de Modelos Culturais a partir da noção de esquema. Para a antropóloga, esquemas culturais derivam de experiências compartilhadas, aprendidas; do que é experienciado pessoalmente por vários membros de um grupo ou daquilo que é comunicado entre eles. Esses esquemas são modelos locais de como operam os mundos natural, sobrenatural, interpessoal e sociopolítico mais amplos.

Eles são utilizados para acessar processos cognitivos e permitem explicar o modo como interpretamos percepções e emoções, reconstruímos memórias e 
planejamos as ações, atuando também na produção e interpretação de comportamento verbal e não verbal. Esquemas são simplificados e podem incluir conceitos genéricos como estereótipos, com ou sem crenças perniciosas, porque esquemas codificam nossas suposições relativas ao que é tipicamente associado com o quê. Os esquemas sempre estão conectados a sentimentos e motivações, servem como traços simbólicos dos esquemas.

Tais esquemas seriam, portanto, organizados em modelos cognitivos que, em contato com as culturas, utilizados em grande espaço temporal, tornam-se modelos culturais. Dessa forma, ferramentas analíticas oriundas da LC estão em total consonância com a proposta de Modelos Culturais, como é o caso das metáforas e frames, que veremos nos tópicos a seguir.

\section{METÁFORAS COMO MODELOS CULTURAIS E A ASSOCIAÇÃO A FRAMES}

Podemos dizer que as metáforas se originam por meio de metáforas primárias. Lakoff e Johnson (1999) mostram algumas metáforas primárias baseadas nos estudos de Narayanan (1997), como apresentado nos exemplos a seguir.

- $\quad$ AFEIÇÃO É CALOR: “Eles me receberam calorosamente”.

- $\quad$ FELIZ É PARA CIMA: “Eu estou para cima hoje”.

- $\quad$ INTIMIDADE É ESTAR PRÓXIMO: “Não nos vemos há anos e por isso nós estamos desafeiçoados".

- DIFICULDADE É ALGO PESADO: “Ela está sobrecarregada de atividades".

- MAIS É PARA CIMA: “Os preços estão altos”.

- $\quad$ CATEGORIAS SÃO CONTÊINERS: “O João está inserido no grupo dos homens". 
- $\quad$ SIMILARIDADE É PROXIMIDADE: “A cor de sua blusa está parelha com a de Joana $\mathrm{D}^{\prime}$ arc".

- $\quad$ ESCALAS LINEARES SÃO CAMINHOS: "A inteligência de Raimundo vai além da conta".

- $\quad$ TEMPO É MOVIMENTO: “Nem vi a hora passar”.

- $\quad$ ESTADOS SÃO LUGARES: “Eu estou imerso em uma depressão muito forte".

- $\quad$ MUDANÇA É MOVIMENTO: “Meu carro está indo fazer a revisão do chassi".

- $\quad$ PROPÓSITOS SÃO DESTINOS: “Ele ainda vai chegar ao mesmo lugar que o Pelé jogando bola".

Tais exemplos constatam o princípio basilar das metáforas primárias: a relação sensório-motora com os aspectos cognitivos organizando as experiências evidenciadas simbolicamente na linguagem. Porém, as metáforas primárias são organizadas socioculturalmente e, desse modo, sofrem variações. Pensemos na metáfora primária VIDA É CAMINHO.

Ao associarmos nossa experiência cultural às metáforas primárias, através de um processo que envolve a produção online de linguagem, podemos construir metáforas como VIDA É UM CAMINHO ESBURACADO, ou, ainda, VIDA É PASSAGEM PARA A MORTE. Essas metáforas, que construímos através da relação entre as metáforas primárias e a contrapartida online e cultural, resultam de redes de integração e são chamadas de metáforas congruentes (KÖVECSES, 2005). Tais metáforas criam variações culturais de acordo com as práticas sociais desenvolvidas por cada comunidade.

Não se tratam de metáforas distintas, congruentes e primárias. O que ocorre é que as metáforas primárias servem de aparato construcional para as metáforas congruentes, que seriam as variações conceituais oriundas das metáforas primárias, organizadas a partir da relação entre o nosso aparato 
sensório-motor e nossa conceptualização do entorno ecológico, ou seja, dos aspectos físicos com os quais nosso corpo interage, como demonstrado nos exemplos anteriores de Lakoff e Johnson (1980).

Ainda de acordo com Kövecses (2005), as metáforas congruentes fornecem às estruturas das metáforas primárias uma contrapartida de estruturas online, ou seja, agrega as experiências concretas das estruturas socioculturais. Para esse entendimento, Kövecses analisa a metáfora conceptual PESSOA COM RAIVA É UM CONTÊINER COM PRESSÃO, como em "eu estou com tanto ódio que acho que irei explodir".

Ele comprova a existência dessa metáfora em diversas culturas, como no Japão, na Hungria, Polônia, China etc. Essa condição da metáfora primária pode causar a impressão de que ela seja um universal. Vejamos o exemplo:

Figura 1 - Mapeamento metafórico

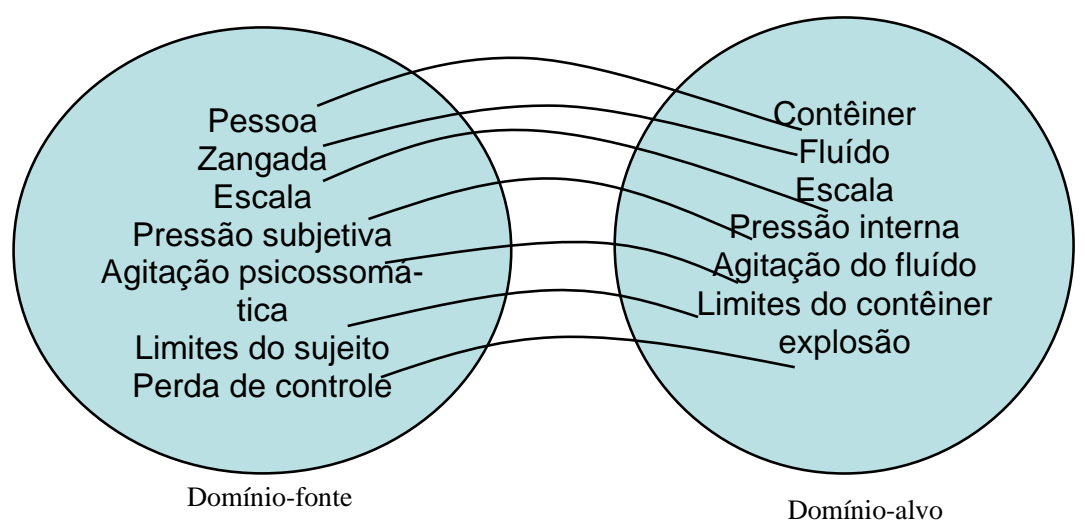

Fonte: Lakoff (1987)

Vemos que os dois domínios, através de mapeamentos, compartilham alguns aspectos: a pessoa e o contêiner; estar zangada com um fluído no contêiner; perda do controle com explosão etc. Porém, percebemos que essa metáfora é extremamente genérica, pois não especifica questões do tipo "onde 
está concentrada a raiva?" Essa questão é abordada diferentemente pelas culturas, de acordo com o linguista. Por exemplo:

\section{Japão: RAIVA ESTÁ NO ESTÔMAGO}

Zulu: RAIVA ESTÁ NO CORAÇÃO

China: RAIVA ESTÁ VOANDO PELO CORPO (Como um fluído de gás)

Essas metáforas são congruentes por sofrerem a influência direta da cultura em questão. As metáforas primárias recebem contornos específicos quando analisadas socioculturalmente, causando as variações metafóricas.

Considerando a indissociável relação entre compreensão metafórica e cultura, não pensamos mais de forma estanque o conceito de frames e metáforas. Ao analisarmos as metáforas no discurso, estamos, concomitantemente, analisando os frames que ali estão sendo acionados por meio dos Modelos Culturais que permitem determinado tipo de organização cognitiva.

Fillmore (1976) define frame como um sistema conceitual. Tal sistema deve ser analisado a partir da estrutura que os comporta. Por exemplo, ao evocar uma mesa, necessito entender em que contexto e situação estou pensando essa mesa. Se for uma mesa em uma sala de aula, o frame será acionado a partir de determinada situação esperada desse contexto, além de considerarmos, portanto, em qual Modelo Cultural esse constructo cognitivo está sendo evocado.

Quando vamos a um teatro, precisamos ter previamente uma compreensão do frame que compõe esse evento. Desse modo, as relações que envolvem o teatro são entendidas através de esquemas de base - imagéticos conjuntamente com slots, que seriam espaços a serem preenchidos por elementos que compõem o determinado frame, como palco, plateia, atores etc.

Além disso, devemos compreender o frame como algo físico, que se organiza em redes neurais em nosso cérebro a partir de informações conceituais que já temos organizadas cognitivamente. Duque explica o modo como frames se organizam 
Frames podem ser organizados em sequências, padrões ou redes. Nesse sentido, a progressão de um leitor durante a leitura de um texto pode ser comparada com uma navegação simultânea de uma rede de conhecimentos estruturada por frames. Por exemplo, em "ele ganhou uma boa gorjeta", a palavra "gorjeta" ativa a experiencia de uma pessoa dando dinheiro a outra pessoa, possivelmente, em um restaurante. Uma pessoa que ouve, lê ou vê a sinalização da palavra "gorjeta" pode inferir que alguém solicitou algo para comer, comeu, pagou e deu dinheiro adicional para o garçom. A quantidade de gorjeta pode também ser inferida. Como regra, é menor que o preço real da refeição e, em alguns países, pode ser calculada como um percentual do custo da refeição (no Brasil, 10\%). O método de apresentação pode variar de país a país. Normalmente, a gorjeta é deixada na mesa junto com o pagamento. No Brasil, o costume é realizar o pagamento e dizer ao garçom para ficar com o troco (DUQUE, 2017, p. 23).

Podemos dizer, portanto, que os Modelos Culturais evocam as metáforas e os frames que são inerentes à cultura em foco. A organização cognitiva considera, portanto, desde os aspectos sensório-motores, que organizam a base da linguagem, às grandes organizações culturais, que são estabelecidas na sociedade, como GOVERNO, SAÚDE, CIDADANIA, JUSTIÇA etc. Esses quadros que são cognitivos e discursivos são denominados por Duque (2015) como frames culturais.

Os frames culturais, portanto, permitem-nos compreender conceitos devidamente enquadrados em modelos culturais, o que nos permite, portanto, relacionar conceitos, como os antes citados, e práticas sociais, uma vez que essa conexão traz coerência na compreensão de nosso entorno.

Tal organização cognitiva passa a ser, portanto, a baliza central de toda nossa compreensão de mundo, evidenciada na forma como produzimos linguagem. A cognição passa a ser integrada entre organismo e ambiente e não apenas corporificada, considerando a relação corpo e mente. Desse modo, as influências perceptuais envolvendo interior e exterior dos indivíduos, antes cunhadas na filosofia, como a relação envolvendo o conceito de razão cartesiana em oposição ao conceito de subjetivismo, deixam de ser vistas como um embate, passando a ser entendidas como uma percepção direta. 
A tradição analítica fundada seminalmente por Lakoff e Johnson (1980) permitiu uma observação cognitiva das metáforas através de seu trato linguístico, criando uma conceituação atrelada fortemente aos elementos da linguagem verbal. Obviamente não podemos reduzir a proposta dos citados autores ao entendimento da linguagem verbal, mas a proposição dos autores, que segue em obras posteriores, de observação da linguagem verbal cria um foco de análise delimitado a essa modalidade de uso linguístico.

Apesar de os estudos metafóricos, seguindo a linha proposta por Lakoff e Johnson (1980), enfocarem consideravelmente a linguagem verbal, autores têm se dedicado ao estudo da metáfora, em outras modalidades e na inter-relação de distintos modos. Especificamente, sobre a multimodalidade Almeida argumenta que

Variados modos semióticos são interconectados pelo(a) conceptualizador(a), em sua elaboração e em sua compreensão dos mais diversos textos multimodais, logo, o sentido é gerado pelas diferentes pessoas conceptualizadoras que promovem a interação desses distintos modos semióticos, já que os multimodais são constituídos pela interconexão de semioses diversas. É, por conseguinte, multimodal qualquer texto em que o(a) conceptualizador(a) utiliza mais de um modo semiótico, em sua elaboração, e os interconecta para a sua compreensão, de tal modo que, por exemplo, o modo visual não é entendido como algo dependente do verbal (ALMEIDA, 2015, p. 102).

O interesse por pesquisas que tratam da observação de metáforas que não estão apenas associadas à linguagem verbal, como as metáforas em sua multimodalidade reportadas por Almeida (2015), fez surgir um novo foco de observação analítica capaz de ampliar o leque de composição empírica das manifestações da metáfora em nossa linguagem cotidiana. A esse novo formato, oriundo da análise de metáforas visuais, Forceville (2009) denominou metáfora multimodal. 
De um modo geral, a proposta de Forceville (2009) amplia o foco de observação. A metáfora multimodal, diferente, por exemplo, de uma metáfora monomodal, ocorre em pelo menos dois modos semióticos. Como mostramos no tópico anterior, as metáforas ocorrem no interior de modelos culturais, criando frames.

Um exemplo de metáfora multimodal pode vir, por exemplo, de uma charge, que pode ser composta pela linguagem verbal e associada à linguagem visual. No tópico seguinte, como assinalado anteriormente, iremos expor a metodologia para em seguida propor uma análise de metáforas multimodais oriundas de charges e relacionadas a uma temática extremamente relevante ao momento atual em que vivemos: a pandemia causada pela Covid-19.

\section{METODOLOGIA}

Analisaremos três charges ${ }^{3}$ pesquisadas através da ferramenta de busca Google relacionadas ao período pandêmico referente ao surto da COVID-19 vivenciado ao redor do mundo no ano de 2020, com enfoque, especificamente, ao período entre fevereiro e agosto de 2020. As charges foram selecionadas após busca pelas seguintes palavras-chave: “covid-19, pandemia, charge". Essas três palavras-chave foram selecionadas por representarem exatamente o que buscamos como corpus de observação.

Em trabalhos anteriores (SANTOS, 2018), desenvolvemos uma metodologia que aplicamos no atual estudo. Nesse trabalho, demos enfoque ao frame ECONOMIA e algumas manchetes veiculadas no site Uol. O resultado apontou para uma organização conceitual alicerçada por metáforas primárias como ECONOMIA É ESCALA (Economia brasileira cresce 4,2\% no $1^{\text {o }}$ trimestre), ou ECONOMIA É TRAJETOR (Analistas preveem desaceleração da economia até

\footnotetext{
${ }^{3}$ Entendemos charges como sendo as peças ilustrativas que buscam satirizar, por meio de traços caricatos, um acontecimento ou um fato contemporâneo.
} 
o fim do ano). Tais organizações conceituais auxiliam na moldura dos Modelos Culturais compartilhados a respeito de ECONOMIA.

As charges são produzidas em um campo multimodal que envolve linguagem verbal e não-verbal (por vezes, apenas não-verbal). Ao analisarmos as charges selecionadas criamos um quadro conceitual que nos permite analisar o atual momento pandêmico, do ponto de vista da mídia, especificamente das charges, que buscam uma linguagem dialógica com o interlocutor e a prática discursiva atual através de insights que são descritos na própria charge. Por se tratar a charge de um possível recurso multimodal, as metáforas que ali subjazem também são construídas através desse recurso, permitindo um outro olhar para as metáforas além do linguístico, que seria a percepção cognitiva que nos permite ativar o frame em questão.

Em nosso caso específico, trata-se do frame DOENÇA, especificado por nós através da COVID-19; porém, essa análise do frame DOENÇA pode ser replicada em qualquer outra patologia, desde que sejam observados os modelos culturais vigentes. Nossa análise se organizará, inicialmente, da evidência da metáfora congruente e a partir dela discorreremos como o frame foi estruturado discursivamente, evocando os Modelos Culturais pertinentes.

\section{ANÁLISES}

Neste capítulo, organizaremos as três charges em seções (5.1, 5.2, 5.3) e faremos uma análise qualitativa dos dados a partir da observação do próprio pesquisador (TALMY, 2000). Essa análise levará em conta, portanto, as metáforas subjacentes associadas aos frames que apontam para Modelos Culturais específicos. A partir dessa definição, faremos um mapeamento do discurso que permeia as práticas discursivas específicas, que envolvem a organização do frame 
cultural (DUQUE, 2015). Nas considerações finais falaremos sobre o efeito de sentido causado pelas charges.

Utilizaremos a caixa alta para marcar as palavras que se referem a metáforas e frames, como, por exemplo, na análise da charge 1 em que temos a metáfora congruente DOENÇA É PESSOA e o frame AEROPORTO.

\subsection{Análise da charge 1 (DOENÇA É PESSOA)}

Figura 2 - Charge 1

10 CASO CONFIRMADO...

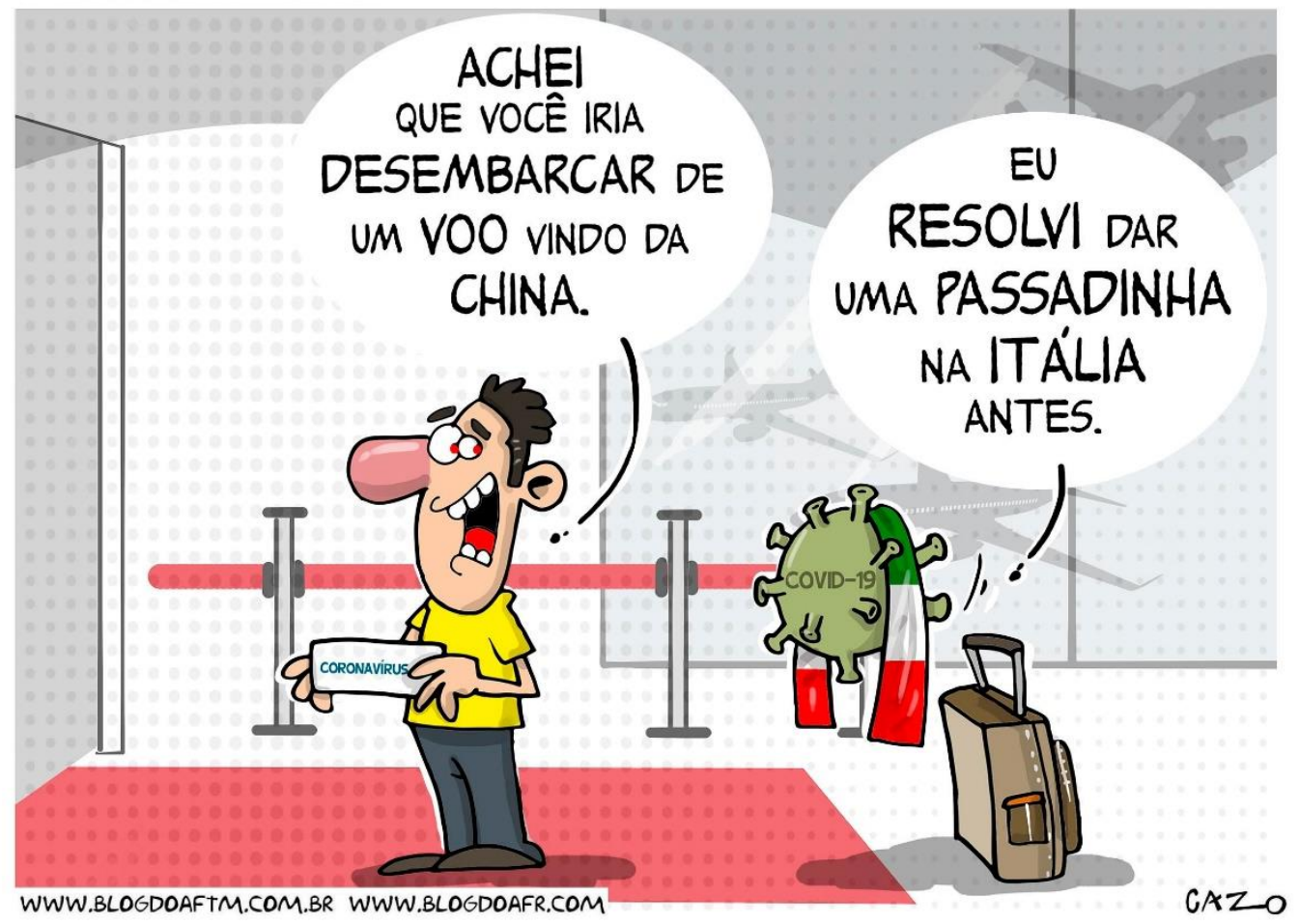

Disponível em: www.blogdoafr.com. Acesso em: 01 ago. 2020, às 14h30min.

A metáfora DOENÇA É PESSOA permite acionarmos um frame em que a doença pode ser uma pessoa, viajar. Nesse caso, a disseminação pandêmica da COVID-19 é facilmente compreendida como se a própria doença, VÍRUS É DOENÇA, referenciada na charge pelo vírus, estivesse se locomovendo pelo mundo e, dessa forma, infectando as pessoas. $\mathrm{O}$ discurso advindo dos Modelos Culturais de que a doença se iniciou na China é acionado através do diálogo observado na charge. 
O frame AEROPORTO é rapidamente recuperado através da imagem, servindo de cenário, bem como o diálogo entre DOENÇA, referenciada na charge através da caricatura do vírus, e uma pessoa em uma fila. A conversa entre ambos é algo que advém do conhecimento de mundo atual, a trajetória da doença, advinda da China, e que se espraia pelo velho continente europeu, com enfoque à Itália, até chegar ao Brasil, ocasionando o primeiro caso relatado oficialmente no país, no final de fevereiro de 2020, em São Paulo.

O enfoque à Itália tem um motivo: a primeira pessoa infectada em nosso país veio da região da Lombardia, Itália. Essas informações pertencem ao frame em questão, que se organiza do conhecimento de mundo atual relacionado à propagação da pandemia. A doença, portanto, seguiu uma trajetória da Ásia para a América, permitindo a organização mental de uma rota de infecção.

\subsection{Charge 2 (NOTÍCIA DE DOENÇA É OBJETO COM MASSA FÍSICA)}

\section{Figura 3 - Charge 2}

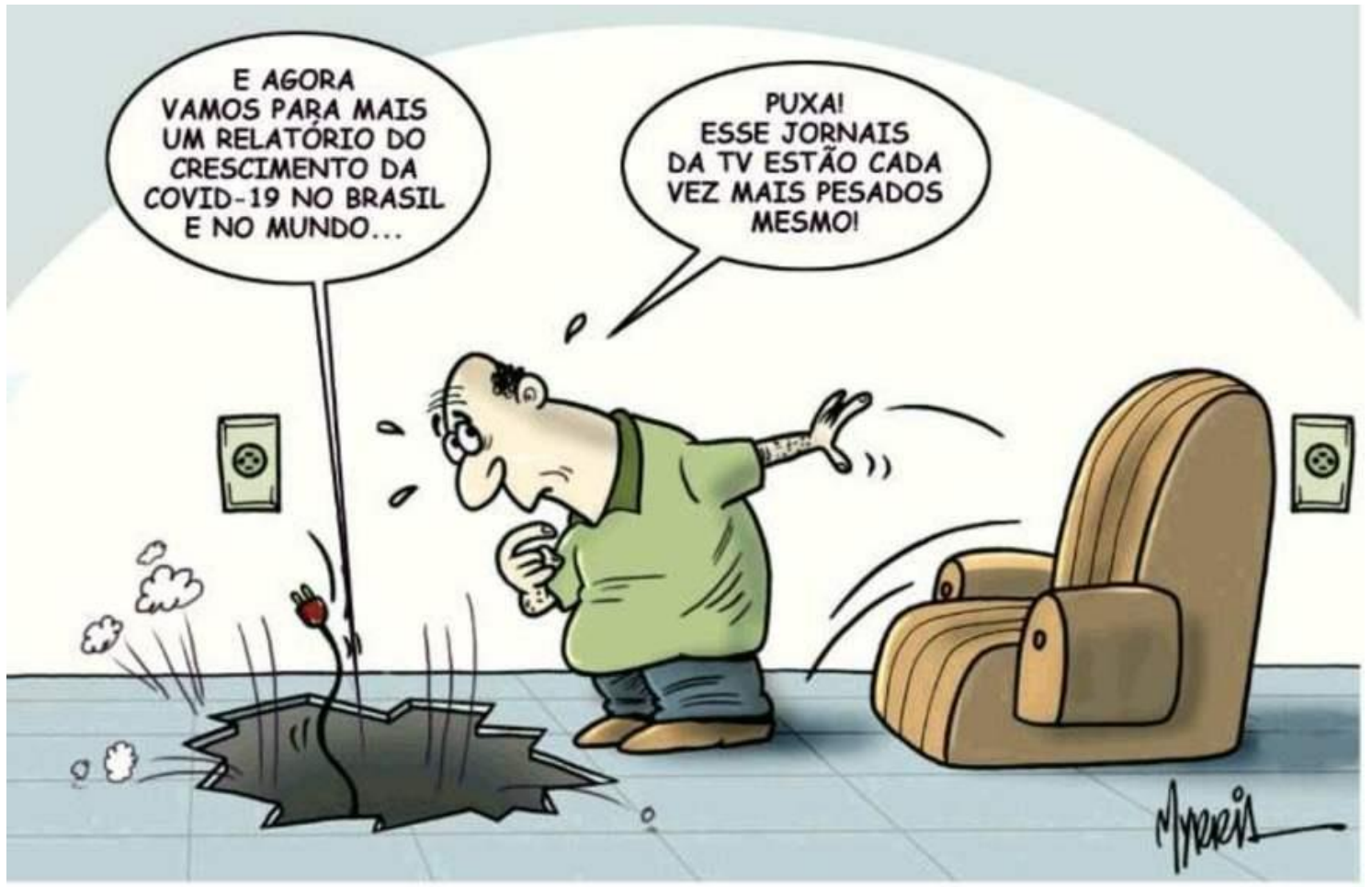

Disponível em: https://www.acritica.com/opinions/23-04-2020. Acesso em: 07 ago. 2020, às 14 h00. 
A metáfora NOTÍCIA DE DOENÇA É OBJETO COM MASSA FÍSICA é recuperada pelo frame cultural envolvendo os noticiários atuais e a forma como as notícias estão sendo veiculadas na mídia. Ao evocarmos na charge o frame CASA compreendemos que se trata de uma sala de estar em que há uma televisão onde notícias sobre a doença estão sendo veiculadas.

A relação de analogia entre o peso da televisão ser tão grande que fez um rombo no chão da sala e a metáfora NOTÍCIA DE DOENÇA É OBJETO COM MASSA FÍSICA permite-nos inferir que o fato da notícia sobre a doença ser algo ruim ser associado a algo pesado por meio da metáfora primária NOTÍCIA RUIM É ALGO PESADO e o seu oposto, embora não evocado, também fica em stand by na compreensão NOTÍCIA BOA É ALGO LEVE. O fato de a televisão ter quebrado o chão da sala, gerando espanto do homem que é o telespectador, evidencia que a notícia é realmente ruim e, por isso, bastante pesada.

\subsection{Charge 3 (DOENÇA É BALÃO DE GÁS)}

Figura 4 - Charge 3

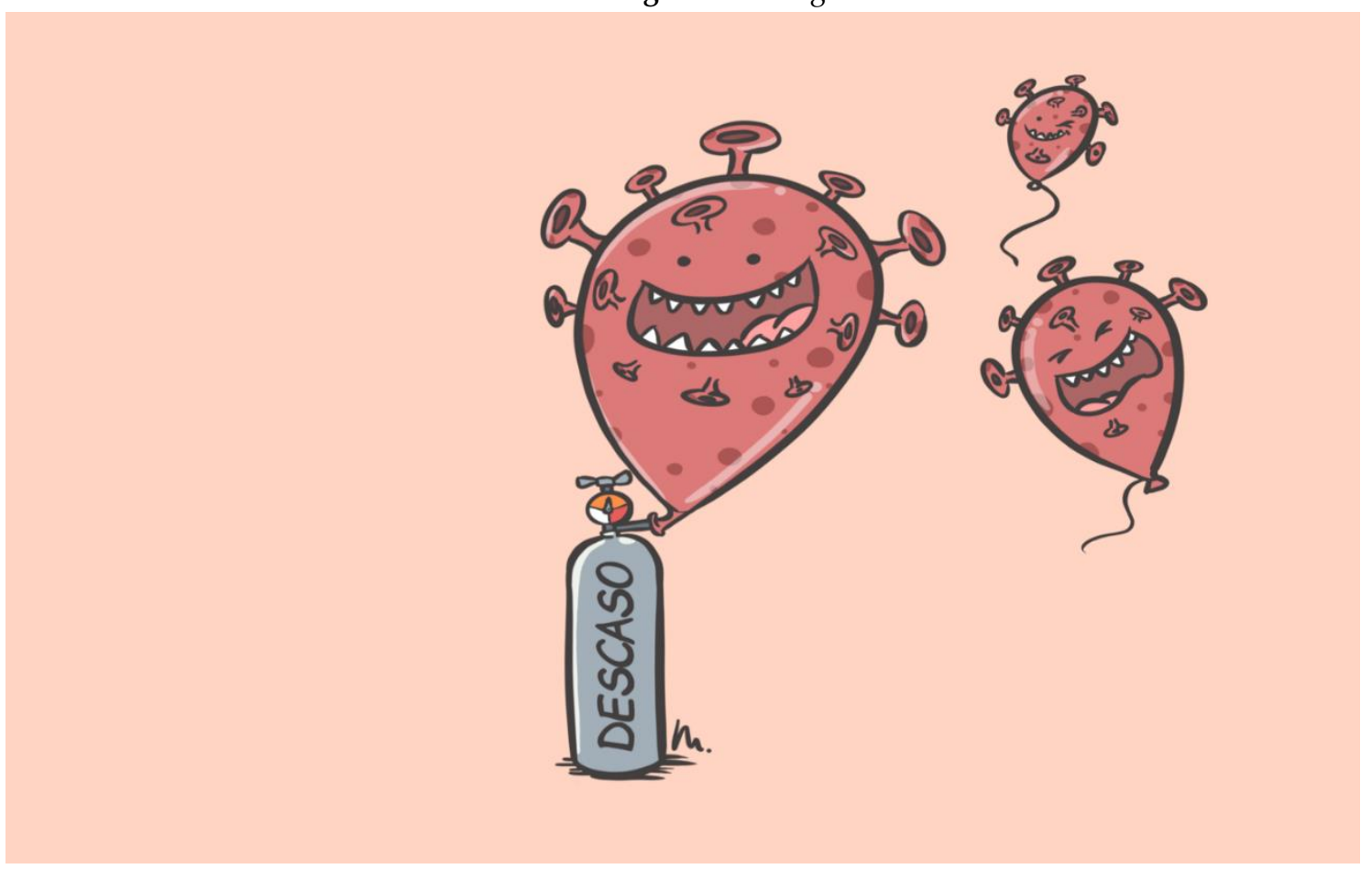

Disponível em: https://www.diariodigital.com.br/charges/subindo/193776/ Acesso em: 07 ago. 2020, às $15 \mathrm{~h} 30$. 
A metáfora DOENÇA É BALÃO DE GÁS é recuperada pelo frame cultural que nos permite relacionar o descaso com a doença promovido por uma grande parte das pessoas e a associação com um balão sendo enchido com gás que, na verdade, seria o descaso. Portanto, BALÃO DE GÁS alicerça a metáfora congruente, sendo o vírus retratado através de cada balão de gás que será enchido, VÍRUS É DOENÇA.

O descaso seria compreendido através da metáfora congruente DESCASO É CONTEÚDO GASOSO que nos permite inflar o BALÃO COVID-19. Como há muito descaso, muitos balões serão enchidos e, dessa forma, fazemos remissão ao grande número de disseminação da doença que tem acontecido, ao recuperarmos os frames culturais. O cuidado com a disseminação seria um fator primordial para tentarmos conter a pandemia, ou seja, teríamos que cuidar do DESCASO ocasionado pela sociedade.

\section{CONSIDERAÇÕES FINAIS}

Após realizarmos a análise das charges, constatamos como a pandemia pode ser compreendida através de metáforas alicerçadas aos Modelos Culturais subjacentes nas charges, acionadas por frames culturais que estão circulando no discurso cotidiano.

Tal organização de frames proporciona construirmos um cenário discursivo da pandemia que estamos enfrentando. Nos três casos analisados, pudemos constatar sempre a relação metafórica da doença sendo conceituada como algo físico, que pode ser uma forma de personificação da doença, como na charge 1 , ou algo que possua massa e seja pesado, como na charge 2 ou, ainda, ser um balão de gás, como vimos na charge 3 . 
Em todas as charges, o acionamento da metáfora é inserido em um frame cultural que faz remissão aos Modelos Culturais específicos, que conseguimos acionar através da compreensão de mundo que fazemos. Desse modo, a forma como se tem noticiado a pandemia, o descaso e o modo como ela está se disseminando são enquadramentos que seriam uma espécie de enfoque do frame DOENÇA.

As construções desses frames dizem respeito a um novo cenário que se tem construído por meio da pandemia causada e os discursos que circundam esse debate, seriam, portanto, formas culturais de se compreendê-la.

As charges causam humor como efeito de sentido, por meio de ironias que são construídas nos frames culturais especificados. Na primeira charge podemos perceber que a quebra do que se espera encontrar em um frame AEROPORTO, através da metáfora DOENÇA É PESSOA, causa o humor, como se a doença pudesse viajar como uma pessoa comum e, desse modo, "disseminar-se".

A segunda charge se alicerça na metáfora NOTÍCIA DE DOENÇA É OBJETO COM MASSA FÍSICA e cria uma relação: quanto mais ruim for a notícia sobre a COVID-19, nesse caso específico, maior será o peso. O humor ocorre exatamente na relação do peso da doença e o fato de quebrar o piso da sala do telespectador. Comumente associamos as construções metafóricas NOTÍCIA RUIM É ALGO PESADO e NOTÍCIA BOA É ALGO LEVE, como, por exemplo, quando dizemos "o noticiário hoje está muito pesado", para nos referirmos a notícias ruins.

E, por fim, podemos perceber que a terceira charge gera o efeito de humor irônico na relação entre o descaso ser um conteúdo gasoso que pode inflar um balão que seria de doença, DOENÇA É BALÃO DE GÁS. Como existe uma grande quantidade de pessoas que reagem com descaso à contaminação, teríamos muito conteúdo para inflar os balões. Dessa forma, a noção de que a contaminação continua "solta pelo ar" é figurativamente demonstrada na charge, 
através dos balões, sendo referenciados como os vírus da doença que estão soltos pelo ar.

Considerando a análise aqui realizada, pretendemos em pesquisas futuras ampliar as observações das charges em um maior número para, dessa forma, criar um panorama discursivo, pautado em observações quantitativas, de como a pandemia está sendo refletida em nossa sociedade. É nosso intuito ampliar a análise das charges para observarmos em maior escala a compreensão de que a pandemia é compreendida através da figuratividade da DOENÇA, muitas vezes com o enfoque sobre o vírus. A manifestação do vírus como sendo algo físico e observável passa a ser uma representação icônica da pandemia e, dessa forma, a compreensão sobre tal problema de saúde é equacionado a uma escala humana de observação, o que facilita a compreensão da sociedade de um modo geral.

\section{REFERÊNCIAS}

ALMEIDA, A. A. D. Brasil, 2015: como a presidenta, seu partido, seus eleitores e seu governo podem ser conceptualizados em rede social. SCRIPTA, Belo Horizonte, v. 20, n. 40, p. 99-118, 2. sem. 2016.

BENNARDO, G.; MUNCK, V. C. Cultural models: genesis, methods, and experiences. New York: Oxford University Press, 2014.

D'ANDRADE, R. Schemas and motivation. In: D'ANDRADE, R.; STRAUSS, C. (Ed.) Human motives and cultural models. New York: Cambridge University Press, 1992. p. 2344 .

DUQUE, P, H. De perceptos a frames: cognição ecológica e linguagem. SCRIPTA. Belo Horizonte, v. 21, n. 41, p. 21-45, 1ํㅗ. 2017.

DUQUE, P, H. Discurso e cognição: uma abordagem baseada em frames. Revista da Anpoll. Florianópolis, n. 39, p. 25-48, Jul./Ago. 2015.

FELTES, H. P. M. Modelos Culturais: teoria, estudos e métodos. Linguagem em (Dis)curso - LemD. Tubarão, SC, v. 18, n. 1, p. 193-213, 2018.

FILLMORE, C. Frame semantics and the nature of language. Annals of the New York Academy of Sciences: Conference on the Origin and Development of Language and Speech. New York, v. 280, p. 20-32, 1976. 
FORCEVILLE, C. Non-verbal and multimodal metaphor in a cognitive framework: agendas for research. In: FORCEVILLE, C.; URIOS-APARISI. Applications of cognitive linguistics: multimodal metaphor. New York: Mouton de Gruyter, 2009, P. 19-44.

KÖVECSES, Z. Metaphor in culture: universality and variation. Cambridge: Cambridge University Press, 2005.

KRONENFELD, D. B. Culture, society, and cognition: collective goals, values, action, and knowledge. New York: Mouton de Gruyter, 2008.

LAKOFF, G. Women, Fire and Dangerous Things: what categories reveal about the mind. Chicago: University of Chicago Press, 1987.

LAKOFF, G.; JOHNSON. Metaphors we live by. Chicago: University of Chicago Press, 1980.

LAKOFF, G.; JOHNSON. Philosophy in the Flesh: the embodied mind and its challenge to Western thought. New York: Basic Books, 1999.

MINSKY, M. A. Framework for representing knowledge: A. I. Memo 306. Cambridge: Massachusetts Institute of Technology, 1985.

NARAYANAN, S. Embodiment in language understanding: sensory-motor representations for metaphoric reasoning about event descriptions. Unpublished PhD Dissertation, Department of Computer Science, University of California, Berkeley, 1997.

QUINN, N. Research on shared task solution. In: STRAUSS, C.; QUINN, N. A Cognitive theory of cultural meanings. Cambridge: Cambridge University Press, 1997. p. 137-188.

SANTOS, R. Y. Metáforas da economia: uma análise da construção de sentido em notícias veiculadas na mídia. Polifonia: Estudos da Linguagem, Mato Grosso, v. 25, p. 175, 2018.

STRAUSS, C. Language and culture in cognitive anthropology. In: SHARIFIAN, F. (Ed.) The Routledge handbook of language and culture. New York: Routledge, 2014. p. 386-400.

TALMY, L. Toward a Cognitive Semantics, v. 1: concept structuring systems. Cambridge: MIT Press, 2000.

Nota do editor:

Artigo submetido para avaliação em: 14 de setembro de 2020.

Aprovado em sistema duplo cego em: 20 de janeiro de 2021. 